\title{
"Beyond workforce": a systemic solution for health service provision in small rural and remote communities
}

\author{
John S Humphreys, John Wakerman, Robert Wells, Pim Kuipers, Judith A Jones and Phil Entwistle
}

\begin{abstract}
T $\mathrm{n}$ Australia, over the past decade, considerable research and many government programs have focused on ways to increase medical workforce supply, recruitment and retention. ${ }^{1-5}$ The limited success achieved to date in redressing rural and remote medical workforce undersupply has stimulated a call for "a continuing and holistic overview of what is actually happening at the grassroots level in providing rural and remote communities with appropriate and safe health care", rather than any more surveys on recruitment and retention. ${ }^{6}$

The problem of how to provide accessible, sustainable, appropriate health care services is most acute in small rural and remote communities, where the increased costs and difficulties of workforce recruitment and retention are compounded by the lack of economies of scale associated with servicing small populations dispersed over vast distances. Research on the need to ensure the provision of sustainable health services has been limited. ${ }^{7-10}$

For this reason, our systematic review identifying the key requirements underpinning sustainable health care services to meet the diverse health needs of small rural and remote communities in Australia is timely. ${ }^{11}$ Here we present the highlights of our review.
\end{abstract}

\section{Delivering primary health care (PHC) services in rural and remote communities}

Geographically large countries like Australia and Canada face enormous problems in servicing the health needs of their populations. ${ }^{12,13}$ In Australia, various health care models have evolved to meet the needs of non-metropolitan inhabitants. Where populations are insufficient to meet the range and threshold requirements necessary to support local health care services, consumers have to travel long distances to larger regional centres or depend on visiting services at irregular intervals, with emergency care provided by the Royal Flying Doctor Service or air ambulance. ${ }^{14}$ Alternatively, consumers forgo care or present late - factors that arguably contribute to the poorer health status of rural and remote residents. ${ }^{15,16}$

While the role of general practice within PHC services is central, the dominant doctor-centred, fee-for-service model may not necessarily be the optimal service delivery model in rural and remote areas. $^{17}$ Increasingly, the need to adopt a comprehensive PHC model involving multidisciplinary teams is recognised. Indeed, Starfield has argued that a PHC approach yields the best health outcomes, particularly in situations of limited resources. ${ }^{18,19}$

\section{Summary of our systematic review of evidence on sustainable PHC models}

Since 1993, Australian governments have funded numerous "innovative" pilot models for small rural and remote communities, few of which have been comprehensively evaluated. Our systematic review of rural and remote PHC models in Australia provided a comprehensive evidence base to underpin effective rural and remote health service policies and programs.

\section{ABSTRACT}

- Successful, "innovative" primary health care (PHC) models exist that have adapted to the specific circumstances of their rural and remote context.

- A typology of discrete, integrated, comprehensive and outreach rural and remote services exists rather than a "one coat fits all" PHC health service model.

- Successful models are characterised by macro-scale environmental enablers (supportive health policy, federalstate relations, and community readiness) and five essential service requirements (workforce organisation and supply; funding; governance, management and leadership; linkages; and infrastructure).

- Service sustainability depends on ensuring that key systemic service requirements are met at the local level in ways that accord with, and are supported by, the broader macro-scale environmental enablers.

- Based on these principles, these model types are amenable to generalisation and evaluation in other regions.

MJA 2008; 188: S77-S80

Our methodology, outlined in detail elsewhere, ${ }^{11}$ identified 68 of some 5391 initial meta-database "hits" that met the search criteria - namely, English-language reports on Australian rural and remote PHC models based on primary or secondary evidence about structural and financial aspects of sustainable service provision.

\section{Typology of rural and remote primary health models}

Our review identified several rural and remote PHC models (Box 1). In recognition of the diversity of rural and remote regions, the actual health service configurations differ significantly. Communities with sufficient population size are able to support discrete health care services, while smaller, more dispersed populations depend on integrated or outreach arrangements. ${ }^{11}$

\section{Service framework of sustainability requirements}

Each successful primary health service model, regardless of its specific design, is characterised by common inter-related and interdependent factors that underpin its sustainability (Box 2). These requirements comprise macro-scale environmental enablers and specific requirements operating at the service level

At the macro level, the policy environment must be conducive to facilitating services that take account of the specific health needs and circumstances of rural and remote communities that are not adequately met through mainstream programs and models. Small rural communities often suffer because national and state policies do not fit every case. In a federated political system, governments at all levels need to agree on outcomes that guide the purpose and nature of the health service in order to avoid unnecessary duplication of 


\section{Typology of rural and remote primary health care service delivery models}

\begin{tabular}{|c|c|c|c|}
\hline $\begin{array}{l}\text { Context: rural- } \\
\text { remote continuum }\end{array}$ & Model category & Health service examples & Rationale for model \\
\hline \multirow[t]{3}{*}{$\begin{array}{c}\text { RURAL } \\
\text { Characterised by } \\
\text { larger, more closely } \\
\text { settled communities }\end{array}$} & Discrete services & $\begin{array}{l}\text { - Walk-in/walk-out models } \\
\text { - Viable models } \\
\text { - University clinics }\end{array}$ & $\begin{array}{l}\text { Discrete health services exist where population catchments } \\
\text { meet essential service requirements (although some } \\
\text { supports may be needed to address workforce recruitment } \\
\text { and retention) }\end{array}$ \\
\hline & Integrated services & $\begin{array}{l}\text { - Shared care } \\
\text { - Coordinated care trials } \\
\text { - Primary health care teams } \\
\text { - Multipurpose services }\end{array}$ & $\begin{array}{l}\text { Service integration maximises access to locally available } \\
\text { services. Local point-of-entry to the health system helps to } \\
\text { coordinate patient care and reduces the need for travel }\end{array}$ \\
\hline & $\begin{array}{l}\text { Comprehensive primary } \\
\text { health care services }\end{array}$ & $\begin{array}{l}\text { - Aboriginal-controlled } \\
\text { community health services }\end{array}$ & $\begin{array}{l}\text { Access to services in small, isolated, high-need communities } \\
\text { is critical where few alternative ways of delivering appropriate } \\
\text { care exist. Community participation and service flexibility are } \\
\text { essential to meet local needs and circumstances }\end{array}$ \\
\hline $\begin{array}{c}\text { REMOTE } \\
\text { Characterised by } \\
\text { small populations } \\
\text { dispersed over } \\
\text { vast areas }\end{array}$ & Outreach services & $\begin{array}{l}\text { - "Hub and spoke" models } \\
\text { - Visiting services } \\
\text { - Fly-in/fly-out models } \\
\text { - Telehealth/telemedicine }\end{array}$ & $\begin{array}{l}\text { These models provide access through virtual or periodic } \\
\text { visiting services to communities too small to support } \\
\text { permanent local services. Outreach models often coexist } \\
\text { with other models }\end{array}$ \\
\hline
\end{tabular}

function, responsibility and funding of the service, and at the same time allow flexibility. The Primary Health Care Access Program and the Aboriginal Coordinated Care Trials are examples of approaches that have allowed for cashing out and pooling of funds in order to meet specific circumstances. ${ }^{11}$ Concurrent with this flexibility, local community involvement with planning, development and evaluation of a service is crucial to ensure acceptance and harmonious working relationships and to maximise the use of services.

At the micro level, several specific service requirements must also be fulfilled. These relate to workforce organisation and supply; funding; governance, management and leadership; service linkages, and infrastructure. These factors are closely inter-related and interdependent. For example, recruitment and retention of the health workforce becomes much less of an issue when adequate infrastructure, good management, professional development opportunities, clear role delineation and a supportive critical mass of practitioners are developed.

\section{Policy implications}

Effective and sustainable rural and remote PHC models provide consumers with access to appropriate quality care within realistic cost constraints. Our review identified a number of critical policy issues relevant to the provision of sustainable primary health services for small rural and remote communities.

Firstly, the inter-relationship between the essential service requirements of sustainable PHC services highlights the need for a systems approach in which components of sustainability are identified and their inter-relationships measured. ${ }^{8}$ Focusing solely on individual components (such as workforce supply) without regard to their relationship to, and the importance of, related parts has had limited impact. Sustainable solutions depend on systematically addressing all the requirements outlined in Box 2 .

Examples of successful models that meet these requirements can be seen in various multipurpose services, coordinated care trials and shared care models - for example, the Mallee Track Health and Community Service in Victoria, the Katherine West Health Board in the Northern Territory, and the Mental Health Initiative in Tasmania, respectively, and other medical, allied health and palliative care models (such as the Easy Entry, Gracious Exit model in New South Wales, the North West Queensland Allied Health Service and the Griffith Palliative Care Service in NSW, respectively).

While these models emerged in response to different impetuses (such as workforce shortage, unacceptable suicide rates in the region, or the need for comprehensive and coordinated primary care), each recognised that their ongoing viability depended on, and benefited from, meeting all these essential service requirements. For example, overcoming the difficulties of attracting and retaining primary health workers in small isolated communities in the Mallee region of Victoria and in north-western regions of Queensland and NSW was addressed by inspirational leadership and flexible workplace initiatives underpinning the development of innovative service models that provided stimulating and professionally rewarding, team-based working environments. Importantly, these models are able to respond flexibly to the changing health services environment and capitalise on new opportunities.

Generalising these models through the local adaptation of the principles we have documented will improve access to PHC services in rural and remote Australia.

Secondly, the provision of appropriate, sustainable PHC services in small rural and remote communities requires fitting local solutions within a wider conducive political environment. ${ }^{20}$ The importance of macro-scale health policies and funding paradigms that underpin the environment of what is possible and what is likely to be supported should not be underestimated. Micro-scale service interventions that are not congruent with macro-scale policies are unlikely to yield sustainable results. Within a rapidly changing health environment, rural and remote health services need to maximise their ability to capitalise on new policy and program opportunities that facilitate local flexibility and make management changes necessary to meet local needs. The importance of developing a harmonious relationship between govern- 


\section{Enablers and requirements of sustainable rural and remote primary health care services}

\section{Environmental enablers}

\section{Supportive policy}

Effective primary health care services in rural and remote communities require an explicit policy framework for sustainable health services that specifically takes into account the unique rural and remote considerations that distinguish this context from that addressed by mainstream programs alone.

\section{Federal-state relations}

Streamlining federal-state roles and responsibilities enables health authorities to develop models appropriate to community needs and circumstances and to avoid inefficiencies and duplication of activities, funding and reporting requirements.

\section{Community readiness}

Community involvement in the identification of health needs and planning of the health service, its ongoing governance and evaluation of the service, and maximising communication between the various stakeholders is critical to successful implementation.

\section{Essential service requirements}

\section{Workforce organisation and supply}

- An appropriate staffing mix to meet community needs;

- A comprehensive recruitment strategy to meet professional and personal needs and family support;

- A retention strategy addressing professional support, continuing professional development, and sustainable after-hours and on-call arrangements; and

- Feasible succession planning strategies.

Funding

- An adequate budget to cover salaries and infrastructure, indexed to meet all operational costs;

- Sustainable and flexible financing to ensure the delivery of appropriate care;

- The facility to pool funds in order to maximise service efficiencies and economies and to respond flexibly to changing health needs; and

- An agreement between all funders, service providers and the community that details funding amount, financing mechanism, agreed objectives, performance indicators and consolidated reporting requirements.

Governance, management and leadership

- Governance structure and processes are clearly defined, implemented and reviewed. Service accreditation is mandatory, and the level and nature of community involvement are identified and agreed;

- Management structure and processes are clearly documented and implemented to ensure that service managers with appropriate skills are available; human resource and finance systems are described; and a risk management plan with respect to workforce supply, key staff, service viability and information technology systems is provided; and

- Champions or leaders from the service, community and government are actively engaged in the support and operation of the health service. A succession plan for potential new leaders is in place.

\section{Linkages}

- Every attempt is made to maximise integrated activity within the health service and ensure coordination with external agencies and services at different levels. Central to effective integration and coordination are agreements with key stakeholders so that clinical referral pathways ensure seamless service; key external stakeholders are identified and roles defined; and key systems are consistent, including standard treatment protocols and information management/information technology systems.

\section{Infrastructure}

- New or upgraded physical infrastructure such as clinics, accommodation, equipment, vehicles and an operating budget to maintain them; and

-Information management/information technology systems appropriate to the service, its catchment population (particularly in areas of high population mobility), and its monitoring and reporting needs. ments, health services, practitioners and communities that is characterised by effective communication and shared goals is especially vital in developing and maintaining appropriate, sustainable health services in small rural and remote communities.

\section{Conclusion}

Health systems worldwide are experiencing a fiscal squeeze resulting from an increased burden of chronic disease due to population ageing, changing consumer expectations, increasing use of technology, and problems of workforce supply. Against this backdrop, providing adequate, good-quality, sustainable health services for many rural and remote communities is particularly problematic in view of their small size, dispersion, and poorer health status compared with larger cities.

Given their diversity, it is clear that a "one coat fits all" model is inappropriate. While a PHC focus on health promotion, illness prevention and early intervention offers the greatest promise of ensuring a long-term improvement in health outcomes, Australians living in non-metropolitan areas still require access to health services that provide diagnosis, treatment and follow-up for existing health problems or for routine check-ups. Whatever the "coat" used to ensure that these health needs are met in a timely and equitable manner, rural and remote health service models will only be sustainable if the service requirements identified by our study of "what works well where" are met in a systematic fashion, and these principles are applied to meet local circumstances.

\section{Competing interests}

None identified.

\section{Author details}

John S Humphreys, BA, PhD, DipEd, Professor of Rural Health

Research ${ }^{1}$

John Wakerman, MB BS, MTropHlth, Director ${ }^{2}$

Robert Wells, BA, Director, ${ }^{3}$ and Executive Director ${ }^{4}$

Pim Kuipers, BA(Hons), MHumServ, PhD, Research Fellow ${ }^{2}$

Judith A Jones, BA(Hons), GradDipAppSci(Comp), MSPD, Research

Fellow ${ }^{1}$

Phil Entwistle, BSc, MTropHlth, PhD, Senior Research Fellow ${ }^{2}$ 


\section{SUPPLEMENT}

1 School of Rural Health, Monash University, Bendigo, VIC.

2 Centre for Remote Health (a joint centre of Flinders University and

Charles Darwin University), Alice Springs, NT.

3 Menzies Centre for Health Policy, Canberra, ACT.

4 College of Medicine and Health Sciences, Australian National

University, Canberra, ACT.

Correspondence: john.humphreys@med.monash.edu.au

\section{References}

1 Holub L, Williams B. The General Practice Rural Incentives Program, development and implementation: progress to date. Aust $J$ Rural Health 1996; 4: 117-127.

2 Humphreys JS, Lyle D, Wakerman J, et al. Roles and activities of the Commonwealth Government university departments of rural health. Aust J Rural Health 2000; 8: 120-133.

3 Joyce CM, Stoelwinder JU, McNeil JJ, et al. Riding the wave: current and emerging trends in graduates from Australian university medical schools. Med J Aust 2007; 186: 309-312.

4 Lawson KA, Chew M, Van Der Weyden MB. A revolution in rural and remote Australia: bringing health education to the bush. Med J Aust 2000; 173: 618-624.

5 Productivity Commission. Australia's health workforce. Research report. Canberra: Productivity Commission, 2005.

6 Kamien M, Cameron WI. Solving the shortage of general practitioners in remote and rural Australia: a Sisyphean task? Med J Aust 2006; 185: 652653.

7 Bryant L, Strasser R. The delivery of sustainable rural and remote health services. Background paper for the Regional Australia Summit. Canberra: Department of Transport and Regional Services, 1999. http://www.infrastructure.gov.au/regional/forum/summit/back_sub/background_papers/ pdf/strasser_paper.pdf (accessed Aug 2007).

8 Humphreys JS, Wakerman J, Wells R. What do we mean by sustainable health services? Implications for rural health research. Aust J Rural Health 2006; 14: 33-35.
9 Kamien M. The viability of general practice in Australia. Med J Aust 2004; 180: 318-319.

10 Rural Doctors' Association of Australia and Monash University School of Rural Health. Viable models of rural and remote practice. Canberra: RDAA, 2003.

11 Wakerman J, Humphreys J, Wells R, et al. A systematic review of primary health care delivery models in rural and remote Australia 1993-2006. Canberra: Australian Primary Health Care Research Institute, 2006. http:// www.anu.edu.au/aphcri/Domain/RuralRemote/Final_25_Wakerman.pdf (accessed Aug 2007).

12 Humphreys JS, Dixon J. Access and equity in Australian rural health services. In: Healy J, McKee M, editors. Accessing health care: responding to diversity. Oxford: Oxford University Press, 2004: 89-107.

13 Romanow RJ, commissioner. Building on values: the future of health care in Canada. Final report. Ottawa: Commission on the Future of Health Care in Canada, 2002.

14 Humphreys JS. Health service models in rural and remote Australia. In: Wilkinson D, Blue I, editors. The new rural health: an Australian text. Oxford: Oxford University Press, 2002: 273-296.

15 Australian Health Ministers' Advisory Council and National Rural Health Alliance. Healthy horizons: a framework for improving the health of rural, regional and remote Australians. Canberra: National Rural Health Policy Sub-committee and National Rural Health Alliance, 2002.

16 Australian Institute of Health and Welfare. Rural, regional and remote health - indicators of health. Canberra: AlHW, 2005. (AlHW Cat. No. PHE 59; Rural Health Series No. 5.)

$17 \mathrm{McDonald} \mathrm{J}$, Hare L. The contribution of primary and community health services. Sydney: University of New South Wales, 2004.

18 Starfield B. Primary care: is it essential? Lancet 1994: 344: 1129-1133.

19 Starfield B. Primary care: balancing health needs, services and technology. Oxford: Oxford University Press, 1998.

20 Kingdon JW. Agendas, alternatives, and public policies. New York: Longman, 2003.

(Received 24 Sep 2007, accepted 19 Dec 2007) 